\title{
Desempenho do Piauçu (Leporinus macrocephalus) Arraçoado com Dietas Contendo Diferentes Teores de Tanino ${ }^{1}$
}

\author{
Luis Gabriel Quintero Pinto², Luiz Edivaldo Pezzato ${ }^{3}$, Edma Carvalho de Miranda ${ }^{4}$, \\ Margarida Maria Barros ${ }^{3}$
}

\begin{abstract}
RESUMO - Este estudo foi conduzido com o objetivo de avaliar o efeito dos taninos sobre o desempenho produtivo e a composição da carcaça do piauçu. Utilizaram-se 21 aquários $(80 \mathrm{~L}$ ) num sistema de fluxo fechado com circulação continua (vazão de $1 \mathrm{~L} / \mathrm{min})$, filtro biológico e temperatura controlada. Empregaram-se 84 peixes com peso médio inicial de 5,06 g, na densidade de quatro por aquário, num delineamento inteiramente casualizado com sete tratamentos e três repetições. As rações foram formuladas de forma a apresentarem-se isoenergéticas (3200 kcal ED/ $\mathrm{kg}$ de ração) e isoprotéicas (30\% PB), com as seguintes composições de tanino total: 0,00; 0,23; 0,46; 0,69; 0,$92 ; 1,37$ e 1,82. Avaliou-se a influência do tanino sobre o desempenho produtivo: ganho de peso, conversão alimentar aparente e taxa de eficiência protéica; a composição corporal dos peixes: proteína bruta da carcaça, extrato etéreo da carcaça, proteína bruta e extrato etéreo dos fígados e gordura visceral; e a relação hepatossomática: índice hepatossomático. Concluiu-se que, embora a presença de até $0,69 \%$ de taninos na ração não tenha comprometido os índices de conversão alimentar aparente e taxa de eficiência protéica das rações, níveis iguais ou superiores a $0,46 \%$ resultaram em ganho de peso significativamente inferior para o piauçu e que a espécie se mostrou sensível à presença de taninos condensados, os quais prejudicaram significativamente o metabolismo e o valor biológico dos nutrientes presentes nas rações.
\end{abstract}

Palavras-chave: barbatimão, desempenho produtivo, Leporinus macrocephalus, piauçu, tanino

\section{Growth Performance of Piauçu (Leporinus macrocephalus) Fed Diets with Different Levels of Tannin}

\begin{abstract}
This experiment was undertaken to evaluate the effect of dietary tannin on growth performance and carcass composition of piauçu, for sixty days. Twenty one aquaria $(80 \mathrm{~L})$ were supplied with dechlorinated tap-water $(1 \mathrm{~L} / \mathrm{min}) \mathrm{in}$ a closed system. Water quality was controled by biologic filter and heater. Fish, with inicial average weight $5.06 \mathrm{~g}$, in a triplicate aquaria, were randomly assigned to each of 7 treatments. Experimental diets were formulated to contain approximately $3,200 \mathrm{kcal}$ of digestible energy, $30 \%$ crude protein and $0.0,0.23,0.46,0.69,0.92,1.37$ and $1.82 \%$ of total tannin. Although $0.69 \%$ of tannin added did not affected apparent feed conversion and protein efficiency ratio, concentrations equal or higher than $0.46 \%$ resulted lower weight gain. Piauçu was sensitive to condensed tannin which had significant harmful effect on metabolism and biological value of dietary nutrients.
\end{abstract}

Key Words: barbatimão, growth performance, Leporinus macrocephalus, piauçu, tannin

\section{Introdução}

Os taninos são polifenóis de estruturas químicas diversas, com peso molecular entre $500 \mathrm{e} 4000 \mathrm{~g} / \mathrm{mol}$ e com capacidade de se ligar com as proteínas e outros polímeros, característica que os define como substâncias antinutricionais endógenas (LIENER, 1980; MUELLER-HARVEY e MCALLAN, 1992; WARREHAM et al., 1994). Os taninos têm grande afinidade pelas proteínas ricas em prolina, não precipitam as proteínas em meios alcalinos ( $\mathrm{pH}$ próximo de 9), porém as precipitam eficientemente em $\mathrm{pH}$ próximo ao ponto isoelétrico destas (LIENER, 1980; CHUBB, 1982; WARREHAM et al., 1994; INPA, 1996).
Baseados na estrutura química, os taninos classificam-se em hidrolisáveis e condensados (WARREHAM et al., 1994). Os hidrolisáveis são poliésteres do ácido gálico ou de um de seus derivados, facilmente hidrolisáveis por ácidos. A exemplo, o ácido tânico tem como resultado da hidrólise a glicose e o ácido gálico. Seu efeito tóxico, causado pela absorção intestinal dos produtos finais da hidrólise, ocasiona hemorragias, gastroenterites, necrose hepática e nefrites, entre outros. São importantes em algumas plantas, principalmente arbóreas, e não parecem estar presentes nos cereais (FIALHO e PINTO, 1992).

Os taninos condensados (pro-antocianidinas) são polímeros flavanóides que produzem antocianidinas

\footnotetext{
1 Parte da Dissertação de Mestrado do primeiro autor.

2 Zootecnista, Prof. Dep. Produção Animal - FMVZ - UNAL - Bogotá, Colômbia. E.mail: dlgquinte@veterinaria.unal.edu.co

3 Zootecnista, Dr., FMVZ-UNESP, Campus de Botucatu - CEP 18618-000 - Caixa Postal 560. E.mail: epezzato@fca.unesp.br

4 Prof. Dra., DZO/UFAL, Campus A.C. Simões s/n, Tabuleiro dos Martins, 57000-000 - Maceió - AL.
} 
sob hidrólise ácida. Estão presentes em alguns dos ingredientes vegetais (soja, sorgo, canola, girassol) usados na confecção de rações comerciais. Representam o grupo mais importante de polifenóis na nutrição animal, em função dos efeitos deletérios no aproveitamento das rações e no desempenho produtivo dos animais (WARREHAM et al., 1994).

A diversidade de efeitos dos taninos é devida às diferenças nas capacidades fisiológicas dos animais e às diferentes reações químicas apresentadas pelos diversos grupos de taninos, fato que demostra a correlação entre o nicho alimentar e a espécie animal (HAGERMAN et al., 1992).

Para alguns monogástricos, como os suínos, as aves e os peixes, os taninos condensados afetam o valor nutricional dos alimentos, como conseqüência da formação de complexos com as proteínas dietárias, pela formação de complexos com os carboidratos e outras macromoléculas alimentares; pela inibição da atividade de várias enzimas digestivas, pela diminuição da absorção de outros nutrientes através da parede celular, devido à formação de complexos com íons divalentes de metais e pela erosão de células epiteliais do intestino (WARREHAM et al., 1994).

Experimentos realizados com ingredientes que contêm taninos, na alimentação de algumas espécies de peixes com estômago e digestão ácida, demostraram menor digestibilidade dos nutrientes, piores taxas de conversão alimentar, queda no desempenho produtivo e baixo depósito lipídico nas carcaças e vísceras (DY PEÑAFLORIDA, 1995; MUKHOPADHYAY, 1997; FAGBENRO, 1999; QUINTERO et al., 2000). Para peixes sem estômago, de digestão alcalina, os taninos condensados não provocaram efeitos deletérios (HEPHER, 1993; BECKER e MAKKAR, 1999), porém os taninos hidrolisáveis mostraram sintomas de intoxicação acumulada (BECKER e MAKKAR, 1999).

Em função da ação antinutricional que os taninos podem causar aos peixes e devido a sua presença em ingredientes vegetais que compõem as rações, desenvolveu-se este estudo com piauçu (Leporinus macrocephalus), utilizando-se um produto concentrado de barbatimão (Dimorphandra mollis) como substância tanante condensada.

\section{Material e Métodos}

A presente pesquisa foi realizada entre maio e agosto de 1999, no laboratório de Nutrição de Organismos Aquáticos da Faculdade de Medicina Veterinária e Zootecnia da UNESP, Campus de Botucatu, unidade integrada ao CAUNESP.

Foram utilizados 21 aquários retangulares de fibra de vidro com capacidade para $80 \mathrm{~L}$ e vazão de $1 \mathrm{~L} / \mathrm{min}$ (18 renovações totais por dia). Usou-se um sistema de fluxo de água fechado com circulação contínua e remoção da amônia através de filtro biológico. Todos os aquários foram dotados de aquecedores de $100 \mathrm{w}$, controlados por termostato, para manter regulada a temperatura da água em valores de conforto para a espécie. Empregou-se um lote de 84 alevinos de piauçu (Leporinus macrocephalus) com peso médio inicial de 5,06 $\pm 0,20 \mathrm{~g}$, na densidade de quatro peixes por aquário, num delineamento inteiramente casualizado com sete tratamentos e três repetições.

As rações experimentais foram confeccionadas de forma a apresentarem-se isoenergéticas (3200 kcal ED/ $\mathrm{kg}$ de ração) e isoprotéicas (30\% PB), constituindo sete tratamentos nos quais se incluíram as seguintes porcentagens de taninos totais: 0,$00 ; 0,23 ; 0,46 ; 0,69 ; 0,92 ; 1,37$ e 1,82 (Tabela 1). Avaliou-se a influência do tanino no desempenho produtivo: ganho de peso (GP), conversão alimentar aparente (CAA), e taxa de eficiência protéica (TEP); na composição corporal dos peixes: proteína bruta da carcaça (PBC), extrato etéreo da carcaça (EEC), proteína bruta do fígado (PBF), extrato etéreo do fígado (EEF) e gordura visceral $(\mathrm{GV})$; e na relação hepatossomática: índice hepatossomático(IHS). A composição percentual dos ingredientes usados na confecção das rações e a composição química das rações experimentais apresentam-se na Tabela 1.

$\mathrm{Na}$ fabricação das rações, os ingredientes foram moídos a granulometria padrão de $2 \mathrm{~mm}$ de diâmetro, misturados manualmente e peletizados. Posteriormente, os péletes foram secos em estufa com ventilação forçada a $55^{\circ} \mathrm{C}$ por 24 horas. Finalmente os péletes foram fracionados e peneirados gradativamente para se obterem diâmetros de 1,3 a $1,7 \mathrm{~mm}$ e 1,7 a $2,7 \mathrm{~mm}$, os quais foram usados sequiencialmente nos primeiros 30 dias e dos 30 aos 60 dias experimentais, respectivamente.

As análises bromatológicas das rações foram realizadas no Laboratório de Bromatologia do Departamento de Melhoramento Nutrição Animal da FMVZ - UNESP Botucatu, segundo os protocolos da ASSOCIATION OF OFFICIAL ANALYTICAL CHEMISTS - AOAC (1984), e a determinação dos teores de taninos foi realizada pelo Laboratório de Nutrição Animal do Centro de Energia Nuclear na Agricultura da Universidade de São Paulo, Campus de Piracicaba.

Os peixes foram alimentados à vontade, quatro vezes ao dia, nos níveis próximos da saciedade, sem 
Tabela 1 - Ingredientes e composição químico-bromatológica das dietas

Table 1 - Ingredients and chemical-bromatological composition of diets

\begin{tabular}{|c|c|c|c|c|c|c|c|}
\hline \multirow[t]{2}{*}{$\begin{array}{l}\text { Ingrediente (\%) } \\
\text { Ingredients }\end{array}$} & \multicolumn{7}{|c|}{$\begin{array}{l}\text { Nível de tanino }(\%) \\
\text { Tannin concentration }\end{array}$} \\
\hline & 0,00 & 0,23 & 0,46 & 0,69 & 0,92 & 1,37 & 1,82 \\
\hline Milho & 31,95 & 31,23 & 30,83 & 29,83 & 29,32 & 27,51 & 26,65 \\
\hline $\begin{array}{l}\text { Corn } \\
\text { Farelo de trigo } \\
\text { Wheat bran }\end{array}$ & 5,00 & 5,00 & 5,00 & 5,00 & 5,00 & 5,00 & 5,00 \\
\hline $\begin{array}{l}\text { Farelo de soja } \\
\text { Soybean meal }\end{array}$ & 52,05 & 52,05 & 52,10 & 52,35 & 52,30 & 52,45 & 52,65 \\
\hline $\begin{array}{l}\text { Farinha de peixe } \\
\text { Fish meal }\end{array}$ & 5,00 & 5,00 & 5,00 & 5,00 & 5,00 & 5,00 & 5,00 \\
\hline $\begin{array}{l}\text { Antioxidante } \\
\text { Antioxidant }\end{array}$ & 0,02 & 0,02 & 0,02 & 0,02 & 0,02 & 0,02 & 0,02 \\
\hline $\begin{array}{l}\text { Óleo de soja } \\
\text { Soybean oil }\end{array}$ & 1,43 & 1,80 & 1,80 & 2,20 & 2,40 & 2,95 & 3,31 \\
\hline $\begin{array}{l}\text { P-bicálcico } \\
\text { Dicalcium phosphate }\end{array}$ & 3,00 & 3,00 & 3,00 & 3,00 & 3,00 & 3,00 & 3,00 \\
\hline $\begin{array}{l}\text { Mistura vit. min. }{ }^{2} \\
\text { Vit. min.mix }\end{array}$ & 0,50 & 0,50 & 0,50 & 0,50 & 0,50 & 0,50 & 0,50 \\
\hline $\begin{array}{l}\text { Alginato } \\
\text { Alginate }\end{array}$ & 0,50 & 0,50 & 0,50 & 0,50 & 0,50 & 0,50 & 0,50 \\
\hline $\begin{array}{l}\text { Vitamina } C^{3} \\
\text { Vitamin } C\end{array}$ & 0,05 & 0,05 & 0,05 & 0,05 & 0,05 & 0,05 & 0,05 \\
\hline $\begin{array}{l}\text { Sal comum } \\
\text { Commun salt }\end{array}$ & 0,50 & 0,50 & 0,50 & 0,50 & 0,50 & 0,50 & 0,50 \\
\hline $\begin{array}{l}\text { Barbatimão } \\
\text { Total }\end{array}$ & $\begin{array}{r}0,00 \\
100,00\end{array}$ & $\begin{array}{r}0,35 \\
100,00\end{array}$ & $\begin{array}{r}0,70 \\
100,00\end{array}$ & $\begin{array}{r}1,05 \\
100,00\end{array}$ & $\begin{array}{r}1,41 \\
100,00\end{array}$ & $\begin{array}{r}2,12 \\
100,00\end{array}$ & $\begin{array}{r}2,82 \\
100,00\end{array}$ \\
\hline $\begin{array}{l}\text { Composição }(\%) \\
\text { Composition }\end{array}$ & & & & & & & \\
\hline $\begin{array}{l}\text { Proteína bruta } \\
\text { Crude protein }\end{array}$ & 30,04 & 29,99 & 29,98 & 30,03 & 30,01 & 30,02 & 30,02 \\
\hline $\begin{array}{l}\operatorname{ED}(D E)^{5}(\mathrm{kcal} / \mathrm{kg}) \\
\text { Relação ED: } \mathrm{P}\end{array}$ & $\begin{array}{r}3207 \\
107\end{array}$ & $\begin{array}{r}3204 \\
107\end{array}$ & $\begin{array}{r}3201 \\
107\end{array}$ & $\begin{array}{r}3208 \\
107\end{array}$ & $\begin{array}{r}3205 \\
107\end{array}$ & $\begin{array}{r}3206 \\
107\end{array}$ & $\begin{array}{r}3198 \\
107\end{array}$ \\
\hline $\begin{array}{l}D E: P \text { ratio } \\
\text { Extrato etéreo } \\
\text { Ether extract }\end{array}$ & 8,74 & 8,82 & 8,87 & 8,66 & 8,88 & 8,66 & 8,87 \\
\hline $\begin{array}{l}\text { Fibra bruta } \\
\text { Crude fiber }\end{array}$ & 4,12 & 4,11 & 4,10 & 4,10 & 4,09 & 4,09 & 4,08 \\
\hline $\begin{array}{l}\text { Tanino total } \\
\text { Total tannin }\end{array}$ & 0,00 & 0,23 & 0,46 & 0,69 & 0,92 & 1,37 & 1,82 \\
\hline $\begin{array}{l}\text { Lisina }^{6} \\
\text { Lysine }\end{array}$ & 1,68 & 1,68 & 1,68 & 1,69 & 1,69 & 1,69 & 1,69 \\
\hline $\begin{array}{l}\text { Metionina } \\
\text { Methionine }\end{array}$ & 0,49 & 0,49 & 0,49 & 0,49 & 0,49 & 0,48 & 0,48 \\
\hline $\begin{array}{l}\text { Cálcio }^{6} \\
\text { Calcium } \\
\mathrm{P}_{\text {disp }} 6,7 \\
\text { Available phosphorus }\end{array}$ & 0,45 & 0,45 & 0,45 & 0,45 & 0,45 & 0,45 & 0,45 \\
\hline
\end{tabular}

${ }^{1} \mathrm{BHT}=$ Butil hidroxi tolueno, antioxidante (antioxidant).

2 Mistura vitamínica e mineral (vitamin and mineral mixture) Supremais, ingrediente/ $/ \mathrm{kg}$ (ingredient $/ \mathrm{kg}$ ): Vitaminas (vitamins): $\mathrm{A}=1.200 .000 \mathrm{UI} ; \mathrm{D}_{3}=200.000 \mathrm{UI}$; $\mathrm{E}=12.000 \mathrm{mg} ; \mathrm{K}_{3}=2400 \mathrm{mg} ; \mathrm{B}_{1}=4800 \mathrm{mg} ; \mathrm{B}_{2}=4800 \mathrm{mg} ; \mathrm{B}_{6}=4000 \mathrm{mg} ; \mathrm{B}_{12}=4800 \mathrm{mg}$; ác. fólico (folic ac) $=1200 \mathrm{mg}$; pantotenato de Ca (panthotenic ac.) $=12.000 \mathrm{mg} ; \mathrm{C}=48.000 \mathrm{mg}$; biotina (biotin) $=48 \mathrm{mg}$; colina (choline) $=65.000 \mathrm{mg}$; niacina (niacin) $=24.000 \mathrm{mg} ;$ minerais (minerals): $\mathrm{Fe}=10.000 \mathrm{mg}$; $\mathrm{Cu}=600 \mathrm{mg} ; \mathrm{Mn}=4000 \mathrm{mg} ; \mathrm{Zn}=6000 \mathrm{mg} ; \mathrm{I}=20 \mathrm{mg} ; \mathrm{Co}=2 \mathrm{mg}$ e Se $=20 \mathrm{mg}$.

3 Vitamina C (2-monofosfato de ácido ascórbico L) (Ascorbic acid).

4 Produto concentrado de Barbatimão (Dimorphandra mollis, Benth) com $65 \%$ taninos totais (Barbatimão extract with $65 \%$ total tannin).

$5 \mathrm{ED}=$ energia digestível $(D E=$ digestible energy).

6 Valor calculado (Calculated value).

$7 \mathrm{P}_{\text {disp }}=$ fósforo disponível (Available phosphorus). 
que houvesse perdas consideráveis. Em dias alternados, os aquários foram sifonados para evitar acúmulo de resíduos orgânicos e garantir a melhor qualidade de água. Os dados de consumo aparente foram registrados diariamente e da diferença final obteve-se o consumo total aparente por tratamento.

O experimento teve duração de 60 dias, os peixes foram pesados ao início e final do período experimental, utilizando-se balança com precisão de duas casas decimais. Determinaram-se adicionalmente o peso final dos fígados, o teor de gordura visceral e a composição química dos fígados e das carcaças dos peixes dos diferentes tratamentos.

Os resultados dos índices zootécnicos foram analisados a partir de estudos de regressão (DRAPER e SMITH, 1981) e complementados com análise de variância para experimentos inteiramente casualizados ( $<<0,01$ ), segundo MARTÍNEZe MARTÍNEZ, (1997), e testes de Duncan para comparação entre médias ( $\mathrm{p}<0,05$ ), segundo COCHRAM e COX, (1976). Todas essas análises foram implementadas utilizando-se os procedimentos REG e GLM do SAS (SASI, 1995).

Os parâmetros físico-químicos da água foram registrados periodicamente, sendo a temperatura da água dos aquários aferida diariamente e controlada na faixa de $26-29^{\circ} \mathrm{C}$, considerada ótima para o crescimento da espécie. Os valores de oxigênio dissolvido $\left(\mathrm{O}_{2} \mathrm{D}\right)$, $\mathrm{pH}$ e amônia foram registrados a cada 15 dias e mantidos nas faixas de: $\mathrm{O}_{2} \mathrm{D}$ maior que $4 \mathrm{ppm} ; \mathrm{pH}$ próximo a 7; e amônia menor que $0,1 \mathrm{ppm}$, segundo as recomendações de BOYD (1990).

\section{Resultados e Discussão}

Os valores médios das variáveis de ganho de peso (GP), conversão alimentar (CA), taxa de eficiência protéica (TEP), índice hepatossomático (IHS), composição de proteína e extrato etéreo do fígado e carcaça (PBF, PBC, EEF e EEC, respectivamente) e gordura visceral (GV) estão apresentados na Tabela 2.

Observou-se efeito significativo $(\mathrm{p}<0,01)$ dos tratamentos sobre o ganho de peso (GP), pelo teste F. Comparando essas médias, de ganho de peso, pelo teste de Duncan, constatou-se que o tratamento $0,23 \%$ de taninos na ração não diferiu do controle e que o controle; 0,46 e $0,69 \%$ de taninos apresentaram-se com similar ganho de peso ( $p>0,05)$. O mesmo ocorreu para os tratamentos 0,92 e $1,37 \%$, sendo que esse último também não diferiu do tratamento com $1,82 \%$ de taninos. Constatou-se que a presença de taninos nas rações resultou em tendência linear decrescente de ganho de peso $(p<0,05)$, com índice de correlação de $83 \%$.

Limites à presença de taninos nas rações para monogástricos (aves e suínos) foram destacados por ROSTAGNO (1999), segundo o qual o sorgo, embora possa substituir até $100 \%$ do milho, por apresentar composição química semelhante, tende a diminuir as respostas de desempenho produtivo, em função do seu alto teor de tanino condensado. A possibilidade de admitir baixos níveis de taninos nas rações, sem que haja prejuízos ao ganho de peso, também foi demostrada em estudos realizados por DY PEÑAFLORIDA (1995) em dietas para camarão marinho, quando avaliou a ação desse agente antinutricional presente nas folhas de mamão (Carica papaia) e de batata doce (Ipoema batatas) e observou que níveis de até $0,044 \%$ de taninos totais na ração não afetaram o ganho de peso.

Tal possibilidade também foi constatada por FABJENRO (1999) em estudos com bagre africano (Clarias gariepinus), quando parte da farinha de peixes foi substituída pelo farelo de feijão alado (Psophocarpus tetragonolobus), e observou-se que a presença de até $0,31 \%$ de taninos totais na ração não prejudicou o ganho de peso dessa espécie. $\mathrm{O}$ mesmo foi constatado por MUKHOPADHYAY (1997) para alevinos da espécie "Rohu" (Labeo rohita) alimentados com rações contendo farelo de "sal" (Shorea robusta). Níveis de taninos de até $0,21 \%$ nessa pesquisa não afetaram o ganho de peso.

Analisando os valores absolutos das médias de GP para os piauçus nesse estudo, observou-se que o tratamento $0,23 \%$ de tanino proporcionou pequena tendência de melhor ganho de peso. Entretanto, níveis iguais ou superiores que $0,92 \%$ de tanino afetaram de forma significativa o ganho de peso dos peixes, como conseqüência de sua ação antinutricional nessa variável.

No sentido de melhor visualizar essas diferenças adotou-se o índice relativo de comparação (IRC\%), atribuindo-se o valor $100 \%$ à média de ganho de peso do tratamento controle. Assim, verificou-se que o resultado apresentado pelo tratamento $0,23 \%$ foi melhor que o controle em $6,73 \%$, enquanto os tratamentos 0,46 e $0,69 \%$ de taninos tendem, em média, a diminuir o ganho de peso em $16,68 \%$, com relação ao controle. Através desse mesmo índice, verifica-se a ação deletéria significativa dessa substância, uma vez que o ganho de peso observado para os tratamentos 0,92 ; 1,37 e $1,82 \%$ de tanino foram respectivamente inferiores em $35,52 \%, 46,30 \%$ e 2,41 vezes ao controle.

Esses resultados contrariam os obtidos por BECKER e MAKKAR (1999), com juvenis de carpa 
1168 Rev. bras. zootec.

Tabela 2 - Ganho de peso (GP), conversão alimentar aparente (CAA), taxa de eficiência protéica (TEP), índice hepatossomático (IHS), proteína bruta da carcaça (PBC), extrato etéreo da carcaça (EEC), proteína bruta do fígado (PBF), extrato etéreo do fígado (EEF) e gordura visceral (GV), dos peixes na fase juvenil, em função dos níveis de tanino na ração

Table 2 - Weight gain (WG), apparent feed:gain ratio (AFG), protein efficiency rate (PER), hepatossomatic index (HSI), crude protein of the carcass $(C P C)$, carcass ether extract $(C E)$, liver crude protein (LCP), liver ether extract (LEE) and visceral fat (VF) of juvenile fishes, in function of the tannin levels in the ration

\begin{tabular}{|c|c|c|c|c|c|c|c|c|}
\hline \multirow{2}{*}{$\begin{array}{l}\text { Variável } \\
(\mathrm{M} \pm \mathrm{dp})^{1} \\
\text { Variable }\end{array}$} & \multicolumn{7}{|c|}{$\begin{array}{c}\text { Nível de tanino }(\%) \\
\text { Tannin level }\end{array}$} & \multirow{2}{*}{$\begin{array}{l}\text { Regressão } \\
\text { Regression } \\
(\mathrm{CV} \% ; \mathrm{R} \%)\end{array}$} \\
\hline & 0,00 & 0,23 & 0,46 & 0,69 & 0,92 & 1,37 & 1,82 & \\
\hline \multirow[t]{2}{*}{$\overline{\mathrm{GP}}(W G)^{\mathrm{A}}(\mathrm{g})$} & $39,70^{\mathrm{ab}}$ & $42,37^{a}$ & $33,55^{\mathrm{b}}$ & $32,69^{b}$ & $25,60^{\mathrm{c}}$ & $21,32^{\mathrm{cd}}$ & $16,46^{\mathrm{d}}$ & $Y=41,535-14,399 x$ \\
\hline & $\pm 7,56$ & $\pm 3,45$ & $\pm 3,37$ & $\pm 1,42$ & $\pm 4,43$ & $\pm 0,57$ & $\pm 1,43$ & $(\mathrm{CV}=12,77 ; \mathrm{R}=83)$ \\
\hline \multirow[t]{2}{*}{$\mathrm{CAA}(A A C)^{\mathrm{A}}$} & $1,13^{\mathrm{ab}}$ & $1,04^{\mathrm{a}}$ & $1,12^{\mathrm{ab}}$ & $1,12^{\mathrm{ab}}$ & $1,36^{\mathrm{bc}}$ & $1,33^{b c}$ & $1,42^{\mathrm{c}}$ & $Y=1,0579+0,202 x$ \\
\hline & $\pm 0,21$ & $\pm 0,10$ & $\pm 0,12$ & $\pm 0,07$ & $\pm 0,19$ & $\pm 0,10$ & $\pm 0,14$ & $(\mathrm{CV}=11,81 ; \mathrm{R}=75)$ \\
\hline \multirow[t]{2}{*}{$\operatorname{TEP}(P E R)^{\mathrm{A}}$} & $3,01^{\mathrm{ab}}$ & $3,22^{\mathrm{a}}$ & $2,99^{\mathrm{ab}}$ & $3,00^{\mathrm{ab}}$ & $2,49^{b c}$ & $2,51^{b c}$ & $2,37^{c}$ & $Y=3,161-0,461 x$ \\
\hline & $\pm 0,51$ & $\pm 0,32$ & $\pm 0,33$ & $\pm 0,18$ & $\pm 0,36$ & $\pm 0,17$ & $\pm 0,25$ & $(\mathrm{CV}=11,55 ; \mathrm{R}=65)$ \\
\hline \multirow[t]{2}{*}{$\operatorname{IHS}(H S I))^{\mathrm{AB}}$} & $1,90^{\mathrm{a}}$ & $1,87^{\mathrm{a}}$ & $1,61^{\mathrm{ab}}$ & $1,69^{a b}$ & $1,35^{\mathrm{b}}$ & $1,43^{b}$ & $1,61^{\mathrm{ab}}$ & $Y=1,801-0,208 x$ \\
\hline & $\pm 0,13$ & $\pm 0,04$ & $\pm 0,24$ & $\pm 0,15$ & $\pm 0,21$ & $\pm 0,10$ & $\pm 0,04$ & $(\mathrm{CV}=8,97 ; \mathrm{R}=52)$ \\
\hline $\operatorname{PBF}(C P L)(\%)^{2}$ & 63,85 & 63,50 & 59,66 & 60,04 & 58,43 & 58,71 & 58,02 & $(\mathrm{CV}=1,19 ; \mathrm{R}=\mathrm{NS})$ \\
\hline $\operatorname{EEF}(E E L)(\%)^{2}$ & 19,88 & 11,48 & 10,63 & 10,74 & 9,07 & 9,48 & 8,23 & $(\mathrm{CV}=3.39 ; \mathrm{R}=\mathrm{NS})$ \\
\hline \multirow[t]{2}{*}{$\operatorname{PBC}(C P C)^{\mathrm{A}}(\%)$} & $62,64^{\mathrm{a}}$ & $64,87^{\mathrm{ab}}$ & $64,22^{\mathrm{ab}}$ & $65,88^{\mathrm{b}}$ & $65,22^{\mathrm{b}}$ & $67,72^{c}$ & $67,52^{c}$ & $\mathrm{Y}=70,701+1,627 \mathrm{x}$ \\
\hline & $\pm 0,54$ & $\pm 1,40$ & $\pm 0,70$ & $\pm 1,32$ & $\pm 1,87$ & $\pm 0,78$ & $\pm 0,83$ & $(\mathrm{CV}=1,40 ; \mathrm{R}=82)$ \\
\hline \multirow[t]{2}{*}{$\operatorname{EEC}(E E C)^{\mathrm{AB}}(\%)$} & $18,50^{\mathrm{a}}$ & $17,29^{b}$ & $16,35^{\mathrm{bc}}$ & $15,75^{\mathrm{c}}$ & $13,92^{\mathrm{d}}$ & $12,09^{\mathrm{d}}$ & $12,14^{\mathrm{d}}$ & $Y=19,037-1,861 x$ \\
\hline & $\pm 0,67$ & $\pm 0,05$ & $\pm 0,54$ & $\pm 0,57$ & $\pm 0,93$ & $\pm 0,25$ & $\pm 0,95$ & $(\mathrm{CV}=4,24 ; \mathrm{R}=84)$ \\
\hline \multirow[t]{2}{*}{$\mathrm{GV}(V F)^{\mathrm{AB}}(\%)$} & $0,50^{\mathrm{a}}$ & $0,41^{\mathrm{ab}}$ & $0,36^{\mathrm{b}}$ & $0,35^{\mathrm{b}}$ & $0,11^{\mathrm{c}}$ & $0,11^{\mathrm{c}}$ & $0,12^{\mathrm{c}}$ & $Y=0,460-0,229 x$ \\
\hline & $\pm 0,09$ & $\pm 0,13$ & $\pm 0,04$ & $\pm 0,04$ & $\pm 0,01$ & $\pm 0,03$ & $\pm 0,05$ & $(\mathrm{CV}=23,32 ; \mathrm{R}=72)$ \\
\hline
\end{tabular}

1 Média \pm desvio-padrão; $n=3$ (Mean \pm standard deviation).

2 As médias das variáveis PBF e EEF foram obtidas homogeneizando os fígados de cada tratamento.

Valores na mesma linha com diferente letra são diferentes $(p<0,05)$.

$\mathrm{CV}=$ coeficiente de variação (coefficient of variation); $\mathrm{R}=$ coeficiente de correlação (coefficient of correlation).

The averages of the variables $C P L$ and EEF were obtained homogenizing the livers of each treament.

Values in the same line with different letter are different $(p<.05)$.

A Efeito linear (Linear effect) $(p<0,01) ; B$ Efeito quadrático (Quadratic effect) $(p<0,01)$.

NS: não-significativo (Not significant) $(p>0,05)$.

comum (Cyprinus carpio), os quais observaram que a inclusão de $2,0 \%$ de tanino de quebracho (Loxopterigium loetzil) (valor próximo de 1,3\% de taninos condensados totais) não afetou o ganho de peso e a taxa de crescimento metabólica. Esses resultados podem ser explicados como conseqüência da digestão alcalina da carpa comum, fato que impede a formação de ligações entre os taninos e as proteínas dos alimentos. Entretanto, as diferenças estatísticas das médias de ganho de peso apresentadas pelo piauçu no presente trabalho confirmam os resultados obtidos por CASTRO et al. (1998), em que níveis de inclusão de até $40 \%$ de sorgo nas rações de tilápia vermelha não comprometeram o ganho de peso da espécie.

Os resultados médios do índice de conversão alimentar aparente (CAA) dos diferentes tratamentos, quando submetidos a análise de variância, revelaram-se altamente significativos $(p<0,01)$. Comparando-se as médias pelo teste de Duncan, observa-se que os tratamentos controle; 0,$23 ; 0,46$ e $0,69 \%$ de tanino na ração foram similares $(p>0,05)$. O mesmo foi observado para os tratamentos 0,$46 ; 0,69 ; 0,92$ e $1,37 \%$ de taninos e ainda entre os tratamentos 0,$92 ; 1,37$ e $1,82 \%$. Observa-se que a presença dos taninos nas rações sobre a CAA resultou em tendência linear crescente, com coeficiente de correlação de $75 \%$.

Comparando os resultados de CAA com os de GP, observa-se que o tratamento que recebeu $0,23 \%$ de taninos revelou pequena tendência em proporcionar melhor resposta que o controle. Por outro lado, a ação negativa dessas substâncias fenólicas sobre a CAA apresentou-se diferente e de forma significativa apenas no tratamento $1,82 \%$ de tanino com relação ao controle, embora o ganho de peso tenha sido afetado de forma significativa a partir da inclusão de $0,92 \%$ de tanino na ração e o mesmo não seja observado para CAA. Tal fato pode ter ocorrido pela ação adstringente dos taninos, uma vez que nesses tratamentos registrou-se menor aceitação da ração, tendo-se observado maior freqüência de ejeção de péletes, corroborando os resultados de BECKER e MAKKAR (1999), quando em estudo com a carpa comum.

Aplicando-se o índice relativo de comparação (IRC\%), com valor $100 \%$ para as médias de CAA 
apresentadas pelo controle, observou-se que o tratamento com $0,23 \%$ de taninos foi $7,96 \%$ melhor que o controle e essa tendência resultou em melhores resultados para os tratamentos 0,46 e $0,69 \%$ de tanino, com média $0,88 \%$. Verificou-se por esse mesmo índice, que, embora não tenha sido detectada diferença significativa quando comparados ao controle, os tratamentos 0,92 e $1,37 \%$ de tanino pioraram a CAA em 20,35 e $17,70 \%$, enquanto para o tratamento $1,82 \%$ de tanino o efeito desse agente antinutricional piorou de forma significativa em $25,26 \%$. As pioras na CAA observadas nesse estudo concordam com as afirmações feitas por FIALHO e PINTO (1992) e ROSTAGNO (1999), segundo as quais o tanino aumenta os valores de CAA das rações para suínos e aves, respectivamente.

Na Tabela 2 estão também apresentados os resultados médios da taxa de eficiência protéica (TEP) dos diferentes tratamentos. Quando essas médias foram submetidas à análise de variância, revelaram-se diferenças altamente significativas entre os tratamentos $(\mathrm{p}<0,01)$. Constatou-se ainda, por meio da análise de regressão, que essas médias tiveram tendência linear decrescente $(\mathrm{p}<0,01)$, com coeficiente de correlação de $65 \%$.

Comparando-se as médias dos diferentes tratamentos pelo teste de Duncan (Tabela 2), observou-se que os tratamentos tiveram respostas estatisticamente similares às obtidas com a CAA. Assim, detectouse a tendência de melhor TEP no tratamento $0,23 \%$ e a pior $(\mathrm{p}<0,05)$ no tratamento $1,82 \%$ de taninos na ração. Essa tendência do tratamento $0,23 \%$ de comportar-se melhor que o controle, também observado para GP e CAA, pode estar relacionada com as propriedades antioxidantes dos taninos, relatados por MAESTRO e BORJA (1993).

Para ressaltar esses resultados e no sentido de melhor visualização dessas diferenças, empregou-se o IRC, aplicando-se o valor de $100 \%$ as médias da TEP do controle. Verificou-se que a TEP do tratamento $0,23 \%$ de taninos mostrou tendência de ser melhor que o controle em $6,98 \%$, e a presença de 0,46 e $0,69 \%$ de tanino piorou a TEP em, respectivamente, 0,66 e $0,33 \%$ do valor registrado pelo controle. Entretanto, embora não diferindo significativamente do tratamento controle, os tratamentos 0,92 e $1,37 \%$ revelaram a tendência de piorar a TEP em 17,28 e $16,61 \%$, respectivamente. Destaca-se, de forma significativa, o efeito do tanino no tratamento $1,82 \%$, o qual piorou a TEP, quando comparado ao controle, através do IRC, em $21,66 \%$. Esses resultados devem-se, pro- vavelmente, às reações das substâncias fenólicas com as proteínas dos alimentos, as quais diminuem a disponibilidade da fração protéica das rações.

Os resultados médios dos tratamentos para o índice hepatossomático (IHS) são também apresentados na Tabela 2. Quando analisados pela análise de variância, revelaram diferenças significativas para tratamentos $(\mathrm{p}<0,01)$. A tendência geral das médias desse índice revelou, pela análise de regressão, relação linear decrescente $(\mathrm{p}<0,05)$, com correlação de $52 \%$.

Ao submeter esses dados médios ao teste de Duncan, demostrou-se que os tratamentos 0,92 e $1,37 \%$ de tanino não diferiram entre si e, que diferiram do controle e do tratamento $0,23 \%$ de tanino $(\mathrm{p}<0,05)$. Demostrou-se ainda que os tratamentos com níveis de tanino igual ou superior a $0,46 \%$ apresentaram-se similares.

Considerando-se a presença de níveis de tanino de até $0,69 \%$, nota-se que os pesos dos fígados, embora com tendência de serem menores em relação ao peso corporal, não diferiram significativamente do tratamento controle. Nos tratamentos 0,92 e 1,37\%, a presença desse fator antinutricional na ração teve influência de forma inversa no peso desse órgão, salvo o observado para o tratamento $1,82 \%$, cujo IHS mostrou-se semelhante aos demais. Tais observações sugerem a possibilidade da ação das substâncias fenólicas nesse órgão. Outra hipótese que pode explicar o aumento do IHS registrado no tratamento $1,82 \%$ é a de que esse nível de inclusão tenha alterado o quadro de normalidade hepática.

A fim de melhor retratar esses resultados, aplicouse o IRC atribuindo-se o valor de $100 \%$ as médias do IHS do tratamento controle. Assim, observa-se que o IHS do tratamento $0,23 \%$ de tanino foi apenas $1,58 \%$ inferior ao controle ( $p>0,05)$, enquanto os tratamentos 0,46 e $0,69 \%$ de tanino foram, em média, $13,15 \%$ inferiores ao controle. Por outro lado, o IRC médio dos tratamentos 0,$92 ; 1,37$ e 1,82 em relação ao controle mostrou-se $22,98 \%$ inferior, destacando assim o efeito prejudicial dos taninos sobre o metabolismo hepático.

A exemplo de ocorrido com o IHS, o conteúdo de $\mathrm{PB}$ e EE dos fígados dos peixes demostrou o efeito dos taninos nesse órgão. Assim, os níveis crescentes de tanino nas rações causaram alterações nos teores de proteína bruta e extrato etéreo, apresentando valores médios, respectivamente, de 63,85 e 19,88\% (controle), 63,50 e $11,48 \%(0,23 \%$ de tanino), 59,66 e $10,63 \%$ (0,46\% de tanino), 60,04 e 10,74\% (0,69\% de tanino), 58,43 e $9,07 \%$ (0,92\% de tanino), 58,75 e $9,48 \%$ (1,37\% de tanino) e 58,43 e $8,23 \%$ ( $1,82 \%$ de tanino). Observou- 
1170 Rev. bras. zootec.

se diminuição dos teores de gordura dos fígados já a partir de níveis de taninos iguais ou superiores a $0,23 \%$ e da proteína bruta, quando a ração continha níveis iguais ou superiores a $0,46 \%$ de taninos, resultados que confirmam a hipótese apresentada em relação à ação deletéria dos taninos no metabolismo hepático.

Constam da Tabela 2 os resultados médios da composição em proteína bruta (PBC) e extrato etéreo (EEC) das carcaças dos peixes dos diferentes tratamentos. Submetendo-se esses dados à análise de variância, observou-se diferença altamente significativa $(\mathrm{p}<0,01)$ para a composição em proteína bruta e extrato etéreo.

Comparando-se as médias de proteína bruta das caraças (PBC), por intermédio do teste de Duncan, constatou-se que a $\mathrm{PBC}$, quando da presença de até $0,46 \%$ de taninos na ração, não diferiu significativamente ( $p>0,05)$ do controle. Por outro lado, os teores de $\mathrm{PBC}$ dos tratamentos 0,$23 ; 0,46 ; 0,69$ e $0,92 \%$ mostraram-se semelhantes $(p>0,05)$ entre si e diferentes $(\mathrm{p}<0,05)$ com relação aos demais. O mesmo ocorreu entre os tratamentos 1,37 e 1,82\% de taninos, os quais não diferiram entre si ( $p>0,05)$, e sim dos demais tratamentos $(\mathrm{p}<0,05)$. Constatou-se ainda através da análise de regressão que essas médias tiveram tendência linear crescente $(\mathrm{p}<0,05)$ com coeficiente de correlação de $82 \%$.

No sentido de melhor observar-se esses resultados, atribuiu-se o IRC $100 \%$ ao valor médio de PBC dos peixes do tratamento controle. Assim, observou-se que os tratamentos 0,23 e $0,46 \%$ de taninos apresentaram tendência média em aumentar a concentração de PBC em 3,04\% comparado com o controle. Os tratamentos 0,69 e $0,92 \%$ de taninos apresentaram maior concentração de PBC, a qual foi, em média, $4,65 \%$ superior ao controle. Destaca-se ainda que as dietas contendo 1,37 e $1,82 \%$ de taninos resultaram em peixes com teores de PBC 7,95\% superiores ao controle.

Os valores médios de extrato etéreo da carcaça (EEC), quando submetidos ao teste de comparação de Duncan (Tabela 2), revelaram que todos os tratamentos que continham tanino diferiram do controle $(p<0,05)$. Esses dados demostram ainda que os tratamentos 0,23 e $0,46 \%$ de tanino foram similares ( $p>0,05)$; o mesmo ocorreu com os tratamentos 0,46 e $0,69 \%$ e os tratamentos $0,92,1,37$ e $1,82 \%$ de taninos. Constatou-se ainda, pela análise de regressão, que essas médias tiveram tendência linear decrescente $(p<0,01)$ com coeficiente de correlação de $84 \%$.

Segundo o mesmo procedimento da PBC, atribuiu-se o IRC $100 \%$ às médias de EEC do tratamento controle. Observou-se que as carcaças dos peixes dos tratamentos 0,23 e $0,46 \%$ de taninos apresentaram-se, em média, 9,08\% inferiores ao controle. Constatou-se também que o tratamento $0,69 \%$ de tanino resultou em carcaças $14,86 \%$ mais magras que o controle e, destacadamente, essa tendência foi observada nos tratamentos $0,92,1,37$ e $1,82 \%$ de tanino, que apresentaram teor médio de extrato etéreo $31,26 \%$ menor que o controle.

A tendência da composição da carcaça dos peixes, em função da maior concentração de proteína bruta como conseqüência da menor deposição lipídica, reflete a ação dessas substâncias fenólicas sobre as enzimas digestivas tripsina, lipase e $\mu$-amilase, envolvidas nos processos metabólicos das proteínas, carboidratos e lipídeos, como explicado por FIALHO e PINTO (1992) e GRIFFITHS (1979).

As alterações na composição química dos fígados e carcaças dos peixes observadas nesse estudo contrariam o resultado obtido por BECKER e MAKKAR (1999) de que a presença de $1,3 \%$ de tanino condensado na ração não alterou a composição da carcaça da carpa comum.

Os valores médios de gordura visceral $(\mathrm{GV})$ dos diferentes tratamentos, quando submetidos à análise de variância revelaram-se altamente significativos $(p<0,01)$. Esses resultados quando submetidos à análise de regressão revelaram-se linearmente decrescentes $(p<0,01)$, com coeficiente de correlação de $72 \%$.

Comparando-se as médias pelo teste de Duncan, observou-se que apenas o tratamento $0,23 \%$ de tanino não diferiu do controle. $\mathrm{O}$ depósito de gordura visceral $(\mathrm{GV})$ dos peixes das dietas contendo 0,23 ; 0,46 e $0,69 \%$ de taninos foi similar $(p>0,05)$ e o mesmo observou-se entre os tratamentos 0,$92 ; 1,37 \mathrm{e}$ $1,82 \%$ de taninos na ração.

Atribuindo-se o IRC 100\% ao tratamento controle, observou-se que, embora não diferindo desse, o tratamento $0,23 \%$ de tanino teve tendência em menor depósito de gordura visceral, com IRC $18 \%$ menor. A quantidade de gordura depositada nas vísceras dos peixes alimentados com as rações que continham $0,46 \mathrm{e}$ $0,69 \%$ de taninos foi, em média, $29 \%$ inferior ao controle. Destaca-se através desse índice a menor deposição de gordura visceral correspondente aos tratamentos, cujo teor de tanino foi maior ou igual a $0,92 \%$ da ração, com média de 77,33\% menor que o controle.

Esses resultados, além de refletir parcialmente o constatado com o IHS e o teor de gordura presente nos fígados, retratam a ação antinutricional dessa substância no metabolismo do piauçu. Considerando-se as variáveis estudadas, pode-se observar que, embora a presença até $0,69 \%$ de taninos na ração não tenha 
prejudicado a CAA e a TEP, sua presença diminuiu o GP de forma significativa a partir da inclusão de $0,46 \%$ desse fator antinutricional. A ação deletéria desse antinutricional foi ainda destacada pela composição em proteína e extrato etéreo das carcaças e do fígado, além da gordura visceral depositada nesses peixes.

Essas observações são explicadas em parte por QUINTERO et al. (2000), quando em estudo realizado com o tanino de barbatimão sobre a digestibilidade aparente da matéria seca, proteína bruta e extrato etéreo de rações completas para tilápia do Nilo. Estes autores concluíram que a presença de até $0,42 \%$ de tanino condensado não prejudica significativamente a digestibilidade dos nutrientes analisados, enquanto níveis iguais ou superiores a $0,63 \%$ têm efeitos deletérios altamente significativos na digestibilidade desses nutrientes.

Assim, demostrou-se que taninos prejudicam o metabolismo dos peixes e o valor nutritivo das rações. Tal quadro impõe limites aos ingredientes que possam conter taninos para que o desempenho produtivo e a própria composição química das carcaças dos peixes não sejam zootecnicamente comprometidas, confirmando as observações de FIALHO e PINTO (1992), DY PEÑAFLORIDA (1995), MUKHOPADHYAY (1997), BECKER e MAKKAR (1999), FAGBENRO (1999), ROSTAGNO (1999) e QUINTERO et al. (2000).

\section{Conclusões}

O piauçu mostrou-se sensível à presença de taninos, os quais prejudicaram significativamente o metabolismo e o valor biológico dos nutrientes presentes nas rações.

Para que o desempenho produtivo dessa espécie não seja prejudicado, recomenda-se concentração inferior a $0,46 \%$ de taninos totais na ração.

\section{Referências Bibliográficas}

ASSOCIATIONOFOFFICIAL ANALYTICALCHEMISTS - AOAC. 1984. Official methods of analysis. Arlington: AOAC. 1097p.

BECKER, K., MAKKAR, H.P.S. 1999. Effects of dietary tannic acid and quebracho tannin on growth performance and metabolic rates of common carp (Cyprimus carpio L.). Aquaculture, 175:327-335.

BOYD, C.E. 1990. Water quality management for ponds fish culture. Development in aquaculture and fisheries science. Amsterdan, Oxford, New York: Elsevier Scientific Publishing Company. 480p.

CASTRO, P.F., CAVALTINI, L.B., SILVA NETO, J.R. et al. Utilização de dietas a base de sorgo em rações de crescimento para a tilápia vermelha (Oreochromis niloticus). In: AQUICULTURA BRASIL'98, 10, 1998, Recife. Anais... Recife: ABRAq, 1998. p.65-72.
CHUBB, L.G. 1982. Anti-nutritive factors in animal feddstuffs. In: HARESTING, W. Studies in agricultural and food science butterworths. Recent Advances in Animal Nutrition. p.21-37.

COCHRAM, W.G., COX, G.M. 1976. Experimental desings. 2.ed. New York: John Wiley and Sons publishing. 243p.

DRAPER, N.R., SMITH, H. 1981. Applied regression analysis. New York: Wiley publishing. 380p.

DY PEÑAFLORIDA, V. 1995. Growth and survival of tiger shrimp fed diets where fish meal is partially replaced with papaya (Carica papaya) or camote (Ipoema batatas) leaf meal. The Israel of Aquaculture, 47(1):25-33.

FAGBENRO O.A. 1999. Formulation and evaluation of diets for the african catfsh, Clarias gariepinus (burchell), made for partial replacement of fish meal with winged bean (Psophocarpus tetragonolobus) seed meal. Aquac. Res., 30:249-257.

FIALHO, E.T., PINTO, H. 1992. Embrapa - Utilização de sorgo em rações para suínos e aves. Concórdia, SC. 16:4-19. (Circular técnica).

GRIFFITHS, D.W. 1979. The inhibition of digestive enzimes by extracts of field bean (Vicia faba). J. Sci. Food and Agric., 30(5):458-462.

HAGERMAN, A.E., ROBBINS, C.T., WEERASURITA, Y., WILSON, T.C., MCARTHUR, C. 1992. Tannin chemistry in relation to digestion. J. Range Manag., 45(1):57-62.

HEPHER, B. 1993. Nutrition of pond fishes. Cambridge: Cambridge University. 406p.

INTITUTO NACIONAL DE PESCA Y ACUICULTURA INPA. 1996. Fundamentos de nutrición y alimentación en acuicultura. Bogotá: INPA. 343p.

LIENER, I.J. 1980. Toxic constituents of plants feedstuffs. New York. 502p.

MAESTRO-DURAN, R.M, BORJA PADILLA, B.R. 1993. Actividad antioxidante de los compuestos fenólicos. Grasas $y$ Aceites, 44(2):101-106.

MARTÍNEZ, R., MARTÍNEZ, N. 1997. Diseño de experimentos. Análisis de datos estándar y no estándar. Santafé de Bogotá: Fondo Nacional Universitario. 479p.

MUELLER-HARVEY, I., MCALLAN, A.B. Tannins: their biochemistry and nutritional properties. Adv. Plant Cell Biochem. Biotehnol, 1:151-217.

MUKHOPADHYAY, N., RAY, K. 1997. The potencial uso of deoiled sal (Shorea robusta) seed meal as a feedstuff in pelleted feed for Indian major carp, rohu, Labeo rohita, (Hamilton) fingerlings. Aquaculture Nutrition, 2:221-227.

QUINTERO PINTO, L.G., PEZZATO, L.E., MIRANDA, E.C. et al. 2000. Ação do tanino na digestibilidade de dietas pela tilápia do Nilo (Oreochromis niloticus). Acta Scientarium, 22(3):677-681.

ROSTAGNO, H.S. Retrospectiva e desafios da produção animal - aves e suínos. In: REUNIÃO ANUAL DA SOCIEDADE BRASILEIRA DEZOOTECNIA, 1999, Porto Alegre. Anais... Porto Alegre: UFRGS, 1999. p.49-64.

STATISTICAL ANALYSIS SYSTEMS INSTITUTE. 1995. User's guide, Version 6, 4.ed. Cary: SAS ${ } / \mathrm{STAT}$, SAS Institute Inc. 365p.

WARREHAM, C.N., WISEMAN, J., COLE, D.J.A. 1994. Processing and antinutritive factors in feedstuffs. In: COLE, D.J.A., VARLEY, M.A. (Eds.) Principles of pig sciences. Nottingham. 427p.

Recebido em: 30/05/00 Aceito em: 26/03/01 